\title{
Solid-phase synthesis and DNA binding studies of dichloroplatinum(II) conjugates of dicarba analogues of octreotide as new anticancer drugs
}

\author{
Flavia Barragán, ${ }^{a, b}$ Virtudes Moreno ${ }^{b}$ and Vicente Marchán $*^{a}$ \\ Received (in $X X X, X X X)$ Xth $X X X X X X X X X 200 X$, Accepted $X t h X X X X X X X X X 200 X$ \\ ${ }_{5}$ First published on the web Xth $X X X X X X X X X 200 X$ \\ DOI: $10.1039 / b 000000 x$
}

The first dichloroplatinum(II) conjugates of dicarba analogues of octreotide, which is expected to act as a 'tumor-targeting device', have been efficiently synthesized following a stepwise solid-phase 10 approach. These compounds emulate the mechanism of cisplatin since they form a 1,2-intrastrand cross-link with two consecutive guanines of an oligonucleotide.

More than 30 years after its discovery, cisdiamminedichloroplatinum(II), cisplatin, and its analogues are 15 still among the most effective anticancer drugs in clinical use. ${ }^{1}$ However, the high toxicity and the inherent or acquired resistance have prompted researchers to explore new strategies based on trans, bifunctional and multifunctional platinum compounds, platinum(IV) prodrugs $^{2}$ or even 20 alternative metal ions such as ruthenium. ${ }^{3}$ In this context, a major challenge in therapy is to achieve the specific delivery of metal-based drugs to cancer cells. This would reduce drug toxicity because normal tissues would not be affected. With this idea in mind, some authors have recently reported the 25 conjugation of platinum complexes to carrier molecules such as folate, peptides that target tumor vasculature or even carbon nanotubes. ${ }^{4}$

In our case we have focused on somatostatin, a potent endocrine hormone implicated in the regulation of many

30 physiological processes, such as secretion, cell division, proliferation and apoptosis, which are modulated by five Gprotein-coupled receptors $\left(\mathrm{sst}_{1-5}\right)$ located in the cell membrane. ${ }^{5}$ Although all receptors are expressed to some degree in different tumors, the overexpression of subtype $s t_{2}$ 35 is by far the most important and this fact has been exploited to deliver radionuclides for molecular imaging or cytotoxic agents into tumor cells. ${ }^{6}$ In order to overcome the short halflife of somatostatin in vivo, hundreds of peptide and nonpeptide analogues have been synthesized, including octreotide $40 \mathbf{1}$, a potent metabolically-stabilized cyclooctapeptide agonist that displays high affinity and specificity to $\mathrm{sst}_{2}$ receptor subtype. $^{7}$

Herein we report on the solid-phase synthesis and characterization of the first dichloroplatinum(II) complex 45 conjugated to octreotide analogues (Scheme 1), as well as DNA interaction studies. Since in these conjugates the peptide moiety is expected to act as a 'tumor-targeting device', the metallic complex must not alter either the pharmacophore sequence, $\mathrm{Phe}^{7}$-D-Trp ${ }^{8}-\mathrm{Lys}^{9}-\mathrm{Thr}^{10}$, or the $\beta$-turn structure ${ }_{50}$ stabilized by the disulfide bond, both of which are fundamental elements for the binding to the receptor.

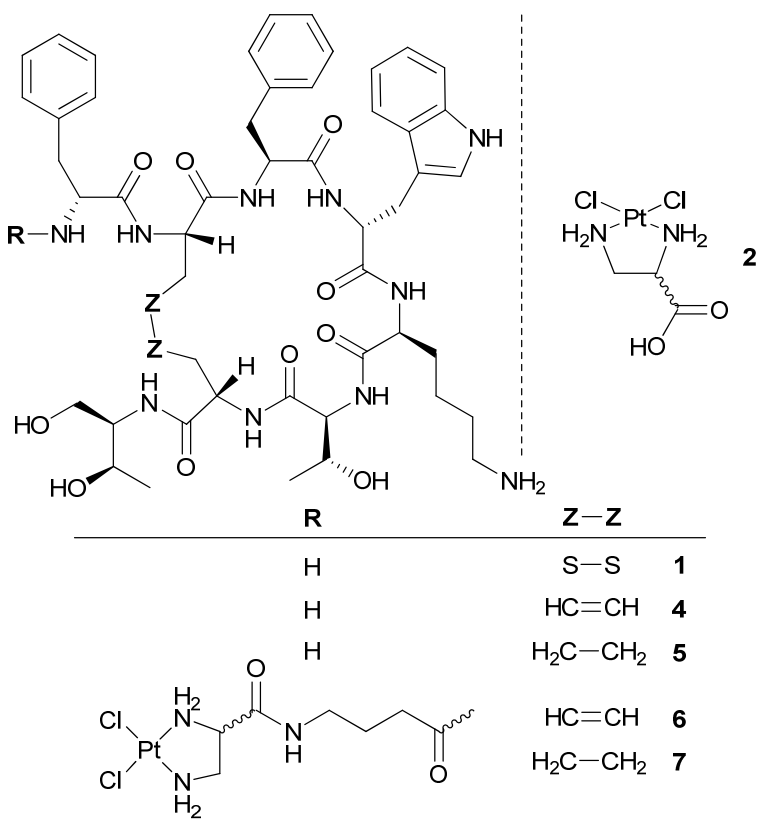

Scheme 1 Structure of the compounds synthesized.

First, as a cisplatin analogue we chose cis-dichloro-(155 (carboxylic acid)-1,2-diaminoethane)platinum(II) complex ([ $\left.\left.\mathrm{PtCl}_{2}(\mathrm{dap})\right]\right), 2$, since the carboxylic function allows the attachment to an amine group of the peptide through an amide bond. This complex was synthesized by reaction between $( \pm)$ 2,3-diaminopropionic acid and $\mathrm{K}_{2} \mathrm{PtCl}_{4}{ }^{8}$

60 Given the kinetic preference of platinum(II) compounds for sulfur-containing species, we were concerned about the stability of the target conjugate between octreotide and 2 . Indeed, the reaction with intracellular thiols such as glutathione has been postulated as the main mechanism of ${ }_{65}$ deactivation of cisplatin and, in some cases, platinum(II) complexes can react and cleave disulfide bonds. ${ }^{9}$ Moreover, a recent study has revealed that octreotide forms two adducts upon reaction with $\left[\mathrm{Pt}(\mathrm{en}) \mathrm{Cl}_{2}\right]$, although the disulfide bond does not to participate. ${ }^{10}$

70 With these precedents in mind, we carried out a preliminary assay in solution by reacting octreotide with 2 using EDC and $\mathrm{N}$-hydroxysuccinimide as coupling reagents in DMF. After 24 $\mathrm{h}$, reversed-phase HPLC analysis showed the formation of a main peak (Fig. 1) which was isolated and characterized by 75 ESI and MALDI-TOF mass spectrometry as the expected dichloroplatinum(II) conjugate of octreotide, $\mathbf{3}$, with a single platinum unit. However, its low stability in water (Fig. 1) 
precludes any biological application as well as the determination of the binding site (two regioisomers might be produced upon the formation of the amide bond with either the N-terminus or the side-chain of Lys ${ }^{9}$ ). To our surprise, MS 5 analysis revealed that in all the side-products a chloride ligand had been lost and that the disulfide bond was not cleaved, suggesting the formation of several adducts differing in the ligands in the sphere of coordination of the metal.
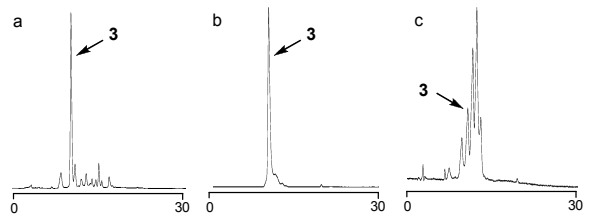

10 Fig. 1 Reversed HPLC traces for conjugate 3: reaction crude (a), purified (b) and after standing for $24 \mathrm{~h}$ in $\mathrm{H}_{2} \mathrm{O}$ (c)

On basis of these results, we focused our work on the synthesis of an octreotide analogue, replacing the disulfide linkage with a cystine isostere. Given the high affinity of 15 platinum(II) for the thioether group, we chose $\mathrm{CH}=\mathrm{CH}$ and $\mathrm{CH}_{2}-\mathrm{CH}_{2}$ linkages since both dicarba analogues of octreotide (4 and 5, respectively; Scheme 1) retain relatively high binding affinity toward the sst $_{2}$ receptor. ${ }^{11}$ Furthermore, onresin ring closing metathesis (RCM) and hydrogenation 20 reactions can be used to generate such analogues. ${ }^{11,12}$ Thus, we envisaged a stepwise solid-phase strategy to regioselectively introduce the platinum(II) moiety at the $\mathrm{N}$ terminal end of both octreotide analogues through a spacer to keep it away from the pharmacophore sequence (Scheme 2).

${ }_{25}$ The linear peptide precursor was assembled manually on a Rink amide resin using standard $\mathrm{Fmoc} / \mathrm{tBu}$ methodology. Once the Fmoc-protected threoninol functionalized as the $p$ carboxybenzaldehyde acetal $^{13}$ had been incorporated, the subsequent Fmoc-protected amino acid derivatives, including 30 allyl glycine replacing both cysteines and $\gamma$-aminoisobutyric acid, were incorporated using HATU as a coupling reagent. Finally, RCM was assayed with second-generation Grubbs catalyst $(0.2 \mathrm{eq})$ at $40^{\circ} \mathrm{C}$ for $18 \mathrm{~h}$ in the presence of $\mathrm{LiCl}$ to minimize aggregation. However, HPLC analysis of an aliquot 35 of resin-cleaved, deprotected peptides (TFA/TIS $/ \mathrm{H}_{2} \mathrm{O}$ $95: 2.5: 2.5$ ) revealed that only $56 \%$ of the linear peptide had been cyclised. We repeated the reaction under microwave irradiation ${ }^{14}$ for $1 \mathrm{~h}$ at $100^{\circ} \mathrm{C}$ and, surprisingly, the efficiency of the RCM was dramatically improved (cyclic/linear peptide 40 93:7, 2:1 mixture of cis and trans diastereomers, respectively) and no oligomerization products were detected, even using a relatively high resin loading $(0.34 \mathrm{mmol} / \mathrm{g})$. The configuration of the double bond was unambiguously established by NMR spectroscopy since a relatively strong NOE between both 45 olefinic protons was only found in the major isomer.

Hydrogenation of unsaturated peptide-resin was accomplished using Wilkinson's catalyst $(0.3 \mathrm{eq})$ for $24 \mathrm{~h}$ at $50^{\circ} \mathrm{C}$ under hydrogen pressure $(50$ Bar). Again, HPLC and high- resolution MS analysis revealed a quantitative reduction ${ }_{50}$ of the double bond under the optimized conditions.

The final step was the linking of the metallic complex onto both cyclic peptide-resins. Once Fmoc group of the spacer had been removed, 2 was coupled using DIPC and HOSu (15 h at rt protected from light). Since TIS scavenger has been 55 described to reduce $\mathrm{PtCl}_{2}$ moiety to metallic platinum, ${ }^{15}$ we carried out cleavage from the resin and removal of protecting groups with a TFA/phenol $/ \mathrm{H}_{2} \mathrm{O}$ cocktail $(95: 2.5: 2.5)$. As shown in Fig. 2, two sets of double peaks $(73 \%, 1: 2$ relative ratio) were obtained for the unsaturated conjugate 6 which 60 accounts from the presence of cis and trans isomers as well as from the use of a racemic platinum(II) complex. All four diastereomers were isolated by preparative HPLC and characterized by MS as the expected dichloroplatinum(II)octreotide conjugates. Similar results were obtained for the ${ }_{65}$ saturated conjugate 7 which appeared as a main double peak (63\%) on HPLC analysis (Fig. 2).

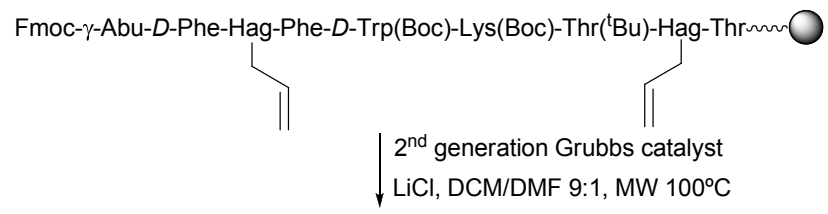

Fmoc- $\gamma$-Abu- $D$-Phe-Hag-Phe- $D$-Trp(Boc)-Lys(Boc)-Thr('Bu)-Hag-Thrurn $\mathrm{Rh}\left(\mathrm{PPh}_{3}\right)_{3} \mathrm{Cl}, \mathrm{H}_{2}$ (50 Bar), $50^{\circ} \mathrm{C}$ DCM/MeOH 9:1

Fmoc- $\gamma$-Abu- $D$-Phe-Hag-Phe- $D$ Trp(Boc)-Lys(Boc)-Thr $\left({ }^{\mathrm{B}} \mathrm{Bu}\right)$-Hag-Thrun

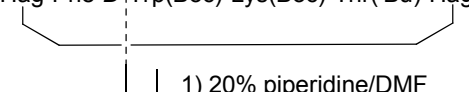

2) 2, DIPC, HOSu, DMF

3) $\mathrm{TFA} /$ phenol $/ \mathrm{H}_{2} \mathrm{O}$

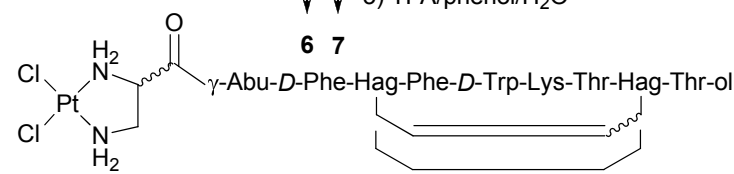

Scheme 2 Schematic representation of the solid-phase approach used for the synthesis of dichloroplatinum(II) conjugates of octreotide.

70 To investigate the stability of such conjugates, 6 (pure cis isomer) was dissolved in $\mathrm{H}_{2} \mathrm{O}$ and left to stand at rt. HPLC analysis revealed that more than $60 \%$ of the product remained unaltered after $24 \mathrm{~h}$ (Fig. 2) which demonstrates that replacement of the disulfide linkage by dicarba isosteres has a 75 positive effect on the overall stability of the conjugate. Interestingly, 6 was completely stable in a $150 \mathrm{mM} \mathrm{NaCl}$ aqueous solution for $24 \mathrm{~h}$.

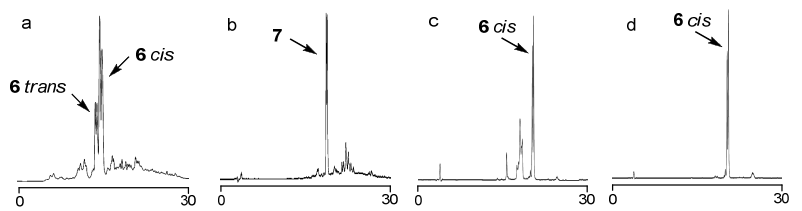

Fig. 2 Reversed HPLC traces for crude conjugate 6 (a) and 7 (b), and of 80 pure 6 cis dissolved in $\mathrm{H}_{2} \mathrm{O}$ (c) or in $150 \mathrm{mM}$ aqueous $\mathrm{NaCl}$ after $24 \mathrm{~h}$ (d).

Since cisplatin and related anticancer drugs effect their cytotoxic action at the level of DNA, in particular by covalently linking to two adjacent guanines on the same strand, ${ }^{1}$ we examined whether the platinum-octreotide 
conjugates retain this binding capacity. As a DNA model we chose a short synthetic oligonucleotide, ${ }^{5}$ dCATGGCT, which contains the target $\mathrm{GpG}$ doublet and gives the expected intrachain Pt-N7/5'G,N7/3'G chelate upon reaction both with ${ }_{5}$ cisplatin and with $\left[\mathrm{Pt}(\mathrm{en}) \mathrm{Cl}_{2}\right] .{ }^{16}$ The reaction between 6 (cis isomer purified as a mixture of two diastereomers) and the oligonucleotide (1:1) was carried out in $\mathrm{H}_{2} \mathrm{O}$ at $37^{\circ} \mathrm{C}$ (Scheme 3). As shown by HPLC, three new broad peaks with higher retention time than the parent oligonucleotide were slowly 10 generated $(20 \%$ after $24 \mathrm{~h})$. MALDI-TOF MS revealed that an adduct had been formed between ${ }^{5}$ dCATGGCT and $\mathbf{6}$, and that both chloride ligands had been lost in all of them. Indeed, MS analysis after enzymatic digestion with 5'- and 3'exonucleases (calf spleen and snake venom ${ }_{15}$ phosphodiesterases, respectively $)^{17}$ confirmed the formation of a chelate between the platinum moiety of $\mathbf{6}$ and the two consecutive guanines of the oligonucleotide chain, 8 (Scheme 3 ). The presence of more than two Pt-N7/5'G,N7/3' G chelates can be attributed to the formation of two positional isomers, 20 differing in the orientation of the peptide moiety towards the oligonucleotide chain. Similarly, reaction with $\left[\mathrm{PtCl}_{2}(\mathrm{dap})\right]$ (2 eq) showed three new peaks upon HPLC analysis (relative ratio $1: 1: 1.3)$ that were isolated and characterized by enzymatic digestion as GpG intra-chain chelates 9. Although 25 the platination yield of the oligonucleotide was higher with $\left[\mathrm{PtCl}_{2}\right.$ (dap) $]$ than with $6 \quad(70 \%$ vs $20 \%$ after $24 \mathrm{~h}$, respectively), the platinum(II)-octreotide conjugate, as previously showed (Fig. 2), is not completely stable in water.

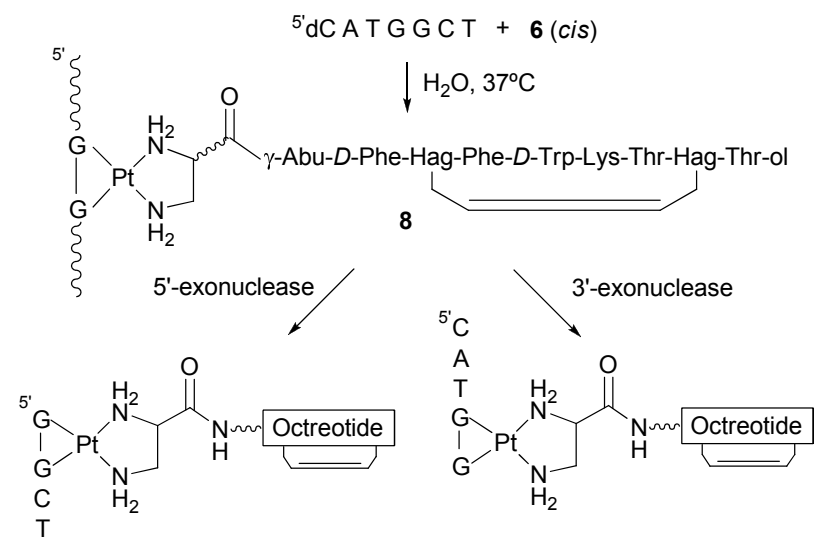

${ }_{30}$ Scheme 3 Formation of the chelate between 6 and the oligonucleotide and its enzymatic degradation with 5' and 3'-exonucleases.

In conclusion, herein we have described a straightforward solid-phase methodology for the synthesis of dichloroplatinum(II) complexes conjugated with dicarba 35 analogues of octreotide. The fact that these conjugates retain the ability to bind to DNA in the same way as cisplatin, opens the door to their use as anticancer drugs. Conjugation to octreotide is expected to increase the concentration of the metal-based drug in the tumor tissue through specific 40 interations with the somatostatin receptor. It is also expected to reduce toxicity and side effects. Efforts are under way to study the affinity and selectivity of these conjugates for sst receptors, as well as to evaluate their biological activity toward several cancer cell lines.
${ }_{45}$ This study was supported by funding from the Ministerio de Educación y Ciencia (CTQ2005-01834, CTQ2007-68014 and CTQ2008-02064), the Generalitat de Catalunya (2005SGR693 and CERBA) and the Programa d'Intensificació de la Recerca (UB).

\section{${ }_{50}$ Notes and references}

${ }^{a}$ Departament de Quimica Orgànica-IBUB, Universitat de Barcelona, Barcelona, E-08028, Spain.E-mail: vmarchan@ub.edu

${ }^{b}$ Departament de Química Inorgànica, Universitat de Barcelona,

Barcelona, E-08028, Spain.

$55 \uparrow$ Electronic Supplementary Information (ESI) available: Synthesis and characterization of conjugates. See DOI: 10.1039/b000000x/

1 Cisplatin. Chemistry and Biochemistry of a Leading Anticancer Drug, ed. B. Lippert, Helvetica Chimica Acta/Wiley-VCH, Zürich/Weinheim, 1999.

2 (a) E. Wong and C. M. Giandomenico, Chem. Rev., 1999, 99, 2451; (b) A. S. Abu-Surrah, Mini-Rev. Med. Chem., 2007, 7, 203.

3 (a) P. C. A. Bruijnincx and P. J. Sadler, Curr. Opin. Chem. Biol., 2008, 12, 197; (b) W. H. Ang and P. J. Dyson, Eur. J. Inorg. Chem., $2006,20,4003$.

4 (a) O. Aronov, A. T. Horowitz, A. Gabizon and D. Gibson, Bioconjugate Chem., 2003, 14, 563; (b) S. Mukhopadhyay, C. M. Barnes, A. Haskel, S. M. Short, K. R. Barnes and S. J. Lippard, Bioconjugate Chem., 2008, 19, 39; (c) S. Dhar, Z. Liu, J. Thomale, H. Dai and S. J. Lippard, J. Am. Chem. Soc., 2008, 130, 11467.

5 G. Weckbecker, I. Lewis, R. Albert, H. A. Schmid, D. Hoyer and C. Bruns, Nat. Rev. Drug Discovery, 2003, 2, 999.

6 (a) U. Haberkorn, M. Eisenhut, A. Altmann and W. Mier, Curr. Med. Chem. 2008, 15, 219; (b) J. Fichna and A. Janecka, Bioconjugate Chem., 2003, 14, 3; (c) L.-C. Sun and D. H. Coy, Drugs Future, 2008, 33, 217; (d) C. M. Huang, Y. T. Wu and S. T. Chen, Chem. Biol., 2000, 7, 453.

7 (a) A. Janecka, M. Zubrzycka and T. Janecki, J. Pept. Res. 2001, 58, 91; (b) W. Bauer, U. Briner, W. Doepfner, R. Haller, R. Huguenin, P. Marbach, T. J. Petcher and J. Pless, Life Sci., 1982, 31, 1133.

8 S. Moradell, J. Lorenzo, A. Rovira, M. S. Robillard, F. X. Aviles, V. Moreno, R. de Llorens, M. A Martínez, J. Reedijk and A. Llobet, J. Inorg. Biochem., 2003, 96, 493.

9 (a) S. J. Berners-Price and P. W. Kuchel, J. Inorg. Biochem., 1990, 38, 305; (b) S. Fakih,V. P. Munk, M. A. Shipman, P. S. Murdoch, J. A. Parkinson and P. J. Sadler, Eur. J. Inorg. Chem., 2003, 6, 1206; (c) H. Wei, X. Wang, Q. Liu, Y. Mei, Y. Lu and Z. Guo, Inorg. Chem., 2005, 44, 6077.

10 V. P. Munk, S. Fakih, P. S. Murdoch and P. J. Sadler, J. Inorg. Biochem., 2006, 100, 1946.

11 D. D'Addona, A. Carotenuto, E. Novellino, V. Piccand, J. C. Reubi, A. Di Cianni, F. Gori, A. M. Papini and M. Ginanneschi, J. Med. Chem., 2008, 51, 512.

12 A. N. Whelan, J. Elaridi, R. J. Mulder, A. J. Robinson and W. R Jackson, Can. J. Chem., 2005, 83, 875.

13 H. P. Hsieh, Y. T. Wu, S. T. Chen and K. T. Wang, Bioorg. Med. Chem., 1999, 7, 1797.

14 A. J. Robinson, J. Elaridi, B. J. Van Lierop, S. Mujcinovic and W. R. Jackson, J. Pept. Sci. 2007, 13, 280.

15 M. S. Robillard, A. R. P. M. Valentijn, N. J. Meeuwenoord, G. A. Van der Marel, J. H. Van Boom and J. Reedijk, Angew. Chem. Int. Ed., 2000, 39, 3096.

16 V. Marchán, V. Moreno, E. Pedroso, A. Grandas, 2001, 7, 808.

17 (a) V. Marchan, E. Pedroso, A. Grandas, Chem. Eur. J., 2004, 10, 5369; (b) B. Alguero, J. López de la Osa, C. González, E. Pedroso, V. Marchán, A. Grandas, Angew. Chem. Int. Ed., 2006, 45, 8194. 